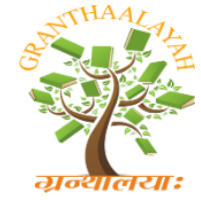

INTERNATIONAL JOURNAL OF RESEARCH GRANTHAALAYAH A knowledge Repository

RAST - 17

\title{
THERMAL RADIATION EFFECT ON MHD NATURAL CONVECTION BOUNDARY LAYER FLOW OVER A PLATE WITH SUCTION (INJECTION) AND VARIABLE VISCOSITY
}

\author{
Jalaja. $\mathbf{P}^{* 1}$, Venkataramana.B. $\mathbf{S}^{2}$, Naveen. $\mathbf{V}^{3}$, Dr. K.R.Jayakumar ${ }^{4}$ \\ ${ }^{*} 1,2,3,4$ Department of Mathematics, K.S.Institute of Technology, India
}

DOI: https://doi.org/10.29121/granthaalayah.v5.i4RAST.2017.3303

\begin{abstract}
The effect of thermal radiation on steady natural convection boundary layer flow over a plate with variable viscosity and magnetic field has been studied in this paper. The effect of suction and injection is also considered in the investigation. The system of partial differential equations governing the nonsimilar flow has been solved numerically using implicit finite difference scheme along with a quasilinearization technique. The thermal radiation has significant effect on heat transfer coefficient and thermal transport in presence of viscosity variation parameter and magnetic field in case of suction and injection.
\end{abstract}

Keywords: Viscosity Variation; Suction; Injection; Thermal Radiation; Magnetic Field.

Cite This Article: Jalaja. P, Venkataramana.B.S, Naveen.V, and Dr. K.R.Jayakumar. (2017). "THERMAL RADIATION EFFECT ON MHD NATURAL CONVECTION BOUNDARY LAYER FLOW OVER A PLATE WITH SUCTION (INJECTION) AND VARIABLE VISCOSITY." International Journal of Research - Granthaalayah, 5(4) RAST, 52-58. https://doi.org/10.29121/granthaalayah.v5.i4RAST.2017.3303.

\section{Introduction}

Convective boundary-layer flows are often controlled by injecting or withdrawing fluid through a porous bounding heated surface. This can lead to enhanced heating or cooling of the system and can help to delay the transition from laminar to turbulent flow. Several researchers studied the effect of suction and injection for different situations on different geometries [1-4]. To calculate precisely the flow and heat transfer rates, it is necessary to take account of variation of viscosity. Also, the study of the flow of a viscous fluid with temperature dependent properties is of great importance in industries. Eswara and Bommaiah [5], Jayakumar.et.al [6] and Lai and Kulacki [7] considered variable viscosity and investigated its effect in various problems. In recent times, the effect of variable viscosity on free convection flow over a plate with an applied magnetic field and suction (injection) is studied by Jayakumar.et.al. [8]. The idea of the proposed 
work is to consider the effect of thermal radiation on MHD free convection boundary layer flow over a plate with variable viscosity and suction (injection).

\section{Analysis}

Consider a semi-infinite porous plate at a uniform temperature $\mathrm{T}_{\mathrm{w} 0}$ which is played vertical in a quiescent fluid of infinite extent maintained at constant temperature $\mathrm{T}_{\infty}$. The plate is fixed in a vertical position with leading edge horizontal. The physical co-ordinates $(\mathrm{x}, \mathrm{y})$ are chosen such that $\mathrm{x}$ is measured from the leading edge in the stream wise direction and $\mathrm{y}$ is measured normal to the surface of the plate. The co-ordinate system and flow configuration are shown in Fig.1. Further, the fluid added (injection) or removed (suction) is the same as that involved in flow. A magnetic field $\mathrm{B}_{0}$ is applied in y-direction normal to the body surface and it is assumed that magnetic Reynolds number is small. The Hall current and displacement current effects have been neglected.

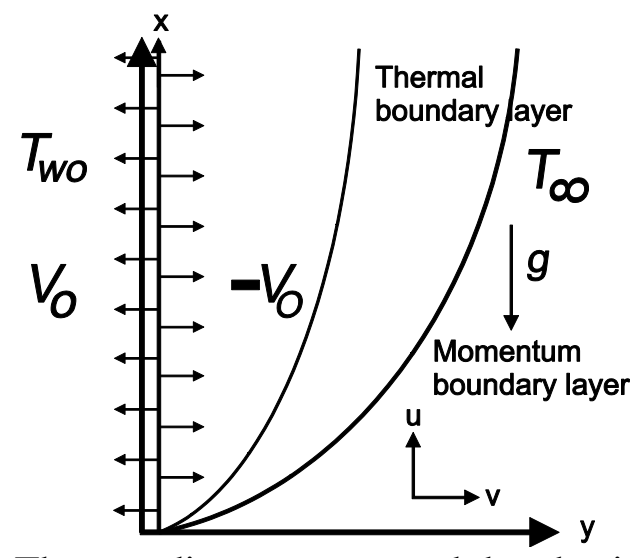

Figure 1: The coordinate system and the physical model.

The fluid is assumed to have constant physical properties except for the fluid viscosity $(\mu)$ which is assumed to be an inverse linear function of the temperature (T) (see Lai and Kulacki [13]), viz.,

$$
\begin{aligned}
& \frac{1}{\mu}=\frac{1}{\mu_{\infty}}\left[1+\gamma\left(T-T_{\infty}\right)\right] \\
& \frac{1}{\mu}=a\left(T-T_{e}\right) \\
& \text { where } \quad a=\frac{\gamma}{\mu_{\infty}} ; \quad T_{e}=T_{\infty}-\frac{1}{\gamma}
\end{aligned}
$$

Under the aforesaid assumptions with Boussinesq's approximation, the equations governing the flow are: 


$$
\begin{aligned}
& \frac{\partial u}{\partial x}+\frac{\partial v}{\partial y}=0 \\
& u \frac{\partial u}{\partial x}+v \frac{\partial u}{\partial y}=g \beta\left(T-T_{\infty}\right)+\frac{1}{\rho_{\infty}} \frac{\partial}{\partial y}\left(\mu \frac{\partial u}{\partial y}\right)-\frac{\sigma B_{0}^{2} u}{\rho} \\
& u \frac{\partial T}{\partial x}+v \frac{\partial T}{\partial y}=\alpha \frac{\partial^{2} u}{\partial y^{2}}-\frac{1}{\rho C_{p}} \frac{\partial q_{r}}{\partial y}
\end{aligned}
$$

The initial and boundary conditions are

$$
\begin{aligned}
& x=0, \quad y>0, \quad u=0, T=T_{\infty} \\
& y=0 ; u=0, v=-v_{0}(\text { for suction }) v=+v_{0} \text { (forblowing), } T=T_{w o} \\
& y \rightarrow \infty ; u=0, T=T_{\infty}
\end{aligned}
$$

Here, the radiative heat flux $q_{r}$ under Roseland approximation, has the form

$$
q_{r}=-\frac{4 \sigma^{*}}{3 k} \frac{\partial T^{4}}{\partial z}
$$

Expanding $T^{4}$ in a Taylor series about $T_{\infty}$ and neglecting higher orders yields:

$$
T^{4}=4 T_{\infty}^{3} T-3 T_{\infty}^{4}
$$

Substituting (5) and (6) into (3) gives,

$$
u \frac{\partial T}{\partial x}+v \frac{\partial T}{\partial y}=\alpha\left(1+N_{R}\right) \frac{\partial^{2} T}{\partial y^{2}}
$$

Introducing the following transformations

$$
\begin{gathered}
\psi=\frac{v^{2} g \beta\left(T_{w 0}-T_{\infty}\right) \xi^{3}}{V_{0}^{3}}\left[f(\eta, \xi) \pm \frac{\xi}{4}\right] ; T=T_{\infty}+\left(T_{w o}-T_{\infty}\right) G(\eta, \xi) \eta=\frac{V_{o} y}{v \xi} \\
\xi=V_{o}\left[\frac{4 x}{v^{2} g \beta\left(T_{w o}-T_{\infty}\right)}\right]^{1 / 4} u=\frac{\partial \psi}{\partial y} ; v=-\frac{\partial \psi}{\partial x}
\end{gathered}
$$

to Eqns.(4), (5) and (10), we see that the continuity Eq.(5) is identically satisfied and Eqns.(5) and (10) reduces, respectively, to

$$
\begin{aligned}
& F^{\prime \prime}+G\left(1-\frac{G}{G e}\right)+3 f F^{\prime}\left(1-\frac{G}{G e}\right)-2 F^{2}\left(1-\frac{G}{G e}\right) \pm \xi F\left(1-\frac{G}{G e}\right)-M F \xi^{2}\left(1-\frac{G}{G e}\right)-\frac{G^{\prime} F^{\prime}}{G e-G}=\xi\left(1-\frac{G}{G e}\right)\left(F F_{\xi}-F^{\prime} f_{\xi}\right) \\
& \operatorname{Pr}^{-1}\left(1+N_{R}\right) G^{\prime \prime}+3 f G^{\prime} \pm \xi G^{\prime}=\xi\left(F G_{\xi^{-}}-G^{\prime} f_{\xi}\right)
\end{aligned}
$$

where

$$
u=\frac{V_{0}^{2} 4 x}{v \xi^{2}} F ; \quad v=-\frac{V_{0}}{\xi}\left(3 f+\xi \xi_{\xi}-\eta F \pm \xi\right) f=\int_{0}^{\eta} F d \eta \quad ; \operatorname{Pr}=\frac{v}{\alpha} ; \quad M=\frac{\sigma B_{0}^{2} v}{\rho V_{0}^{2}} ; N_{R}=\frac{8 \sigma T_{\infty}^{3}}{3 k^{2}}
$$


It is remarked here that the upper sign in Eqns.(9) and (10) is taken throughout for suction and the lower sign for blowing (injection).

The transformed boundary conditions are

$\mathrm{F}=0 ; \mathrm{G}=1$ at $\eta=0$

$\mathrm{F}=0 ; \mathrm{G}=0$ as $\eta \rightarrow \infty$ for $\xi \geq 0$

The local skin friction parameter and heat transfer parameter can be expressed as

$$
\begin{gathered}
\tau_{w}=\frac{V_{0}}{g \beta\left(T_{w 0}-T_{\infty}\right)}\left(\frac{\partial u}{\partial y}\right)_{y=0}=\xi\left(F^{\prime}\right)_{\eta=0} \\
Q=\frac{v}{V_{0}\left(T_{w 0}-T_{\infty}\right)}\left(\frac{\partial T}{\partial y}\right)_{y=0}=-\frac{1}{\xi}\left(G^{\prime}\right)_{\eta=0}
\end{gathered}
$$

Here, $\mathrm{u}$ and $\mathrm{v}$ are velocity components in $\mathrm{x}$ and $\mathrm{y}$ direction; $\mathrm{F}$ is dimensionless velocity; $\mathrm{T}$ and $\mathrm{G}$ are dimensional and dimensionless temperatures, respectively; $\xi, \eta$ are transformed co-ordinates; $\psi$ and $\mathrm{f}$ are the dimension and dimensionless stream functions respectively; $\mathrm{Pr}$ is the Prandtl number; $v, \alpha$ are respectively kinetic viscosity and thermal diffusivity; $w_{0}$ and $\infty$ denote conditions at the edge of the boundary layer on the wall and in the free stream respectively and prime (') denotes derivatives with respect to $\eta$.

The dimensionless temperature $G$ and viscosity ratio $\mu / \mu \infty$ are redefined as follows:

$$
G=\frac{T-T_{e}}{T_{w}-T_{\infty}}+G e \text { and } \quad \text { hence } \quad \frac{\mu}{\mu_{\infty}}=\frac{G e}{G e-G}
$$

where Ge is constant, called viscosity variation parameter, which is defined by

$$
G e=\frac{T_{e}-T_{\infty}}{T_{w}-T_{\infty}}=\frac{-1}{\gamma\left(T_{w}-T_{\infty}\right)}=\text { constant }
$$

and its value is determined by viscosity characteristics of the fluid under consideration and operating temperature difference $\Delta \mathrm{T}=\mathrm{T}_{\mathrm{w}}-\mathrm{T}_{\infty}$.

It may be remarked here that, if $\mathrm{Ge}$ is large (i.e., $\mathrm{Ge} \rightarrow \infty$ ) the effect of variable viscosity can be neglected. On the other hand, for a smaller value of $\mathrm{Ge}$, either the fluid viscosity changes markedly with temperature or operating temperature difference is high. In either case, the variable viscosity effect is expected to become very significant. Also, it may be noted here that, liquid viscosity varies differently with temperature than that of gas and therefore, it is important to note that $\mathrm{Ge}<0$ for liquids and $\mathrm{Ge}>0$ for gases when the temperature difference $\Delta \mathrm{T}$ is positive.

It is worth mentioning here that when $\mathrm{N}_{\mathrm{R}}=0.0$ Eqns.(12) and (13) reduces to

$$
\begin{aligned}
& F^{\prime \prime}+G\left(1-\frac{G}{G e}\right)+3 f F^{\prime}\left(1-\frac{G}{G e}\right)-2 F^{2}\left(1-\frac{G}{G e}\right) \pm \xi F\left(1-\frac{G}{G e}\right)-M F \xi^{2}\left(1-\frac{G}{G e}\right)-\frac{G^{\prime} F^{\prime}}{G e-G}=\xi\left(1-\frac{G}{G e}\right)\left(F F_{\xi}-F^{\prime} f_{\xi}\right) \\
& \operatorname{Pr}^{-1} G^{\prime \prime}+3 f G^{\prime} \pm \xi G^{\prime}=\xi\left(F G_{\xi}-G^{\prime} f_{\xi}\right)
\end{aligned}
$$

which are exactly same as those of Jayakumr et al. [8]. 


\section{Results and Discussion}

The set of partial differential Eqns.(9) and (10) along with the boundary conditions (12) has been solved numerically employing an implicit finite difference scheme with a quasilinearization technique which is presented great detail in[9].
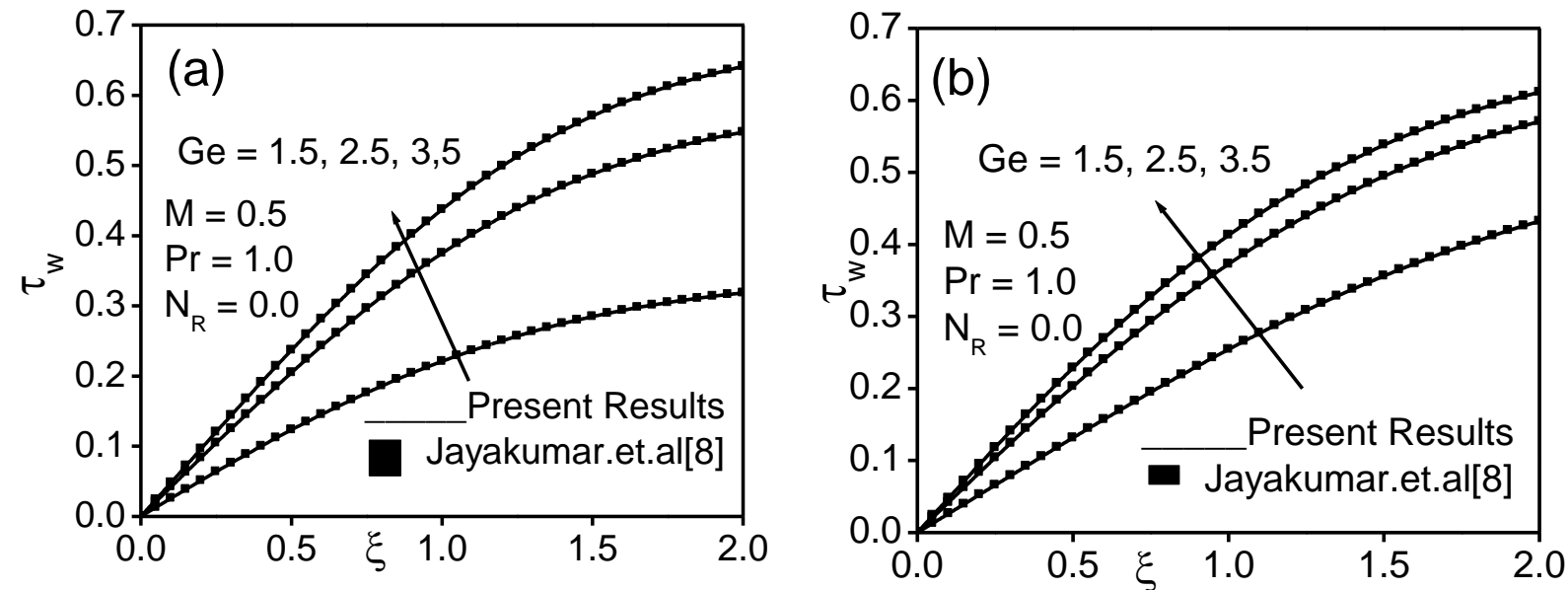

Figure 2: Comparison of skin friction parameter for (a) Suction (b) Injection with those of Jayakumar et al. [8]

The numerical results for various physical parameters are represented in the form of graphs for $\operatorname{Pr}=1.0$. The skin friction and heat transfer parameters $\left(\tau_{w}, Q\right)$ for suction [See Fig.2 (a)] and injection [See Fig.2 (b)] have been obtained by solving the Eqns.(17) and (18) in the absence of magnetic field and compared with those of Merkin [2]. Further, the steady state skin friction and heat transfer results with viscosity variation parameter in presence of magnetic field $(\mathrm{M}=0.5)$ are compared with those of Jayakumar et al.[8] [See Fig.3(a) for suction] and [See Fig.3(b) for injection] by solving the Eqns.(19) and (20). Our results are found to be in excellent agreement, with the above studies.
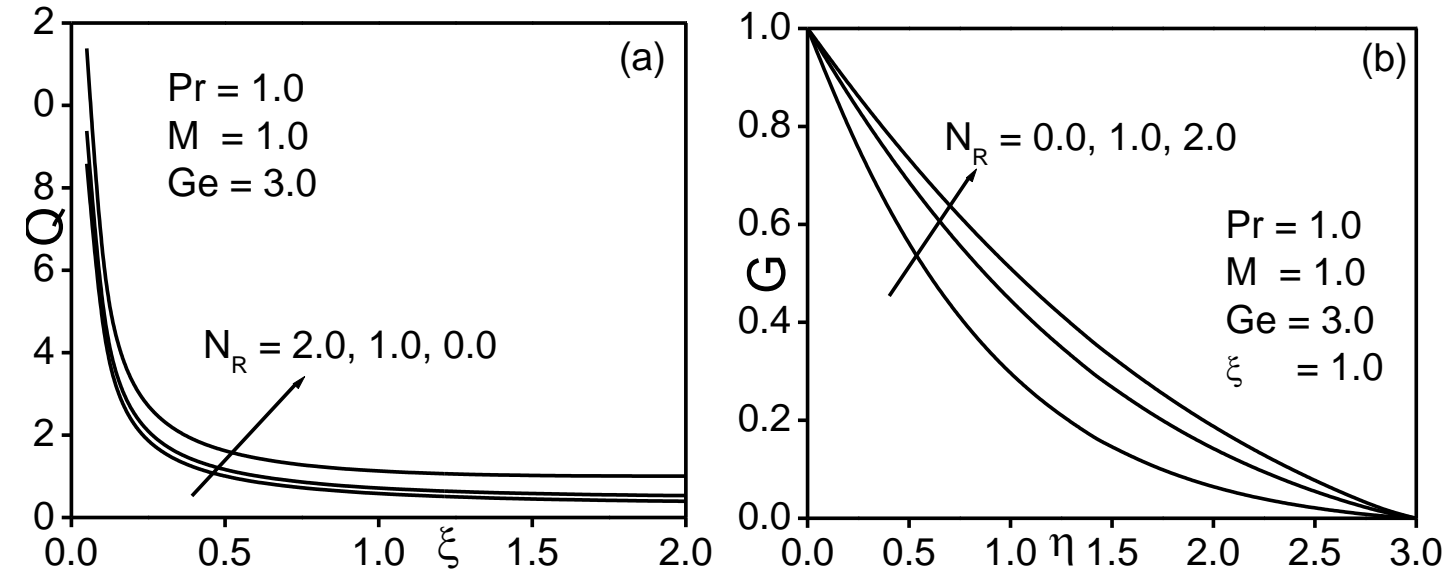

Figure 3: The effect of thermal radiation on (a) Heat transfer parameter and (b) Temperature for Suction

The effect of thermal radiation (NR) on heat transfer parameter $(\mathrm{Q})$ and on temperature $(\mathrm{G})$ in case of suction in presence of magnetic field $(\mathrm{M}=1.0)$ and viscosity variation parameter 
$(\mathrm{Ge}=3.0)$ is presented for different values of stream wise coordinate $(\xi)$ in the Fig.3.It is clearly noted from the graphs that the heat transfer decreases and the thermal boundary layer thickness increases with the increase of thermal radiation parameter. In fact the percentage of decrease of heat transfer parameter is $54.81 \%$ and the percentage of increase in $\mathrm{G}$ is $21.55 \%$ at $\xi=1.0$ from $\mathrm{N}_{\mathrm{R}}=0.0$ to $\mathrm{N}_{\mathrm{R}}=2.0$.
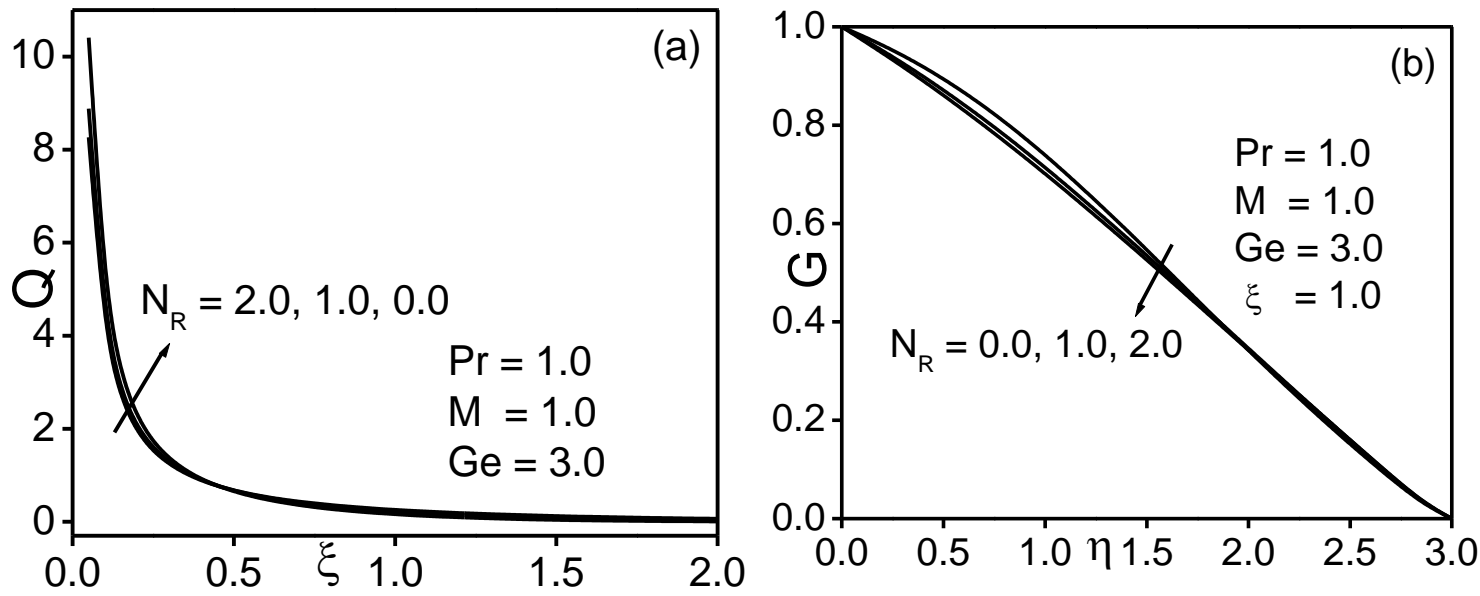

Figure 4: The effect of thermal radiation on (a) Heat transfer parameter and (b) Temperature for Injection

Fig.4 depicts the effect of thermal radiation $\left(\mathrm{N}_{\mathrm{R}}\right)$ on heat transfer parameter $(\mathrm{Q})$ and on temperature $(\mathrm{G})$ for injection in presence of magnetic field $(\mathrm{M}=1.0)$ and viscosity variation parameter $(\mathrm{Ge}=3.0)$. The results are qualitatively similar and quantitatively different as compared to suction. In deed the percentage of decrease of heat transfer parameter is $9.3 \%$ and the percentage of increase in $G$ is $3.9 \%$ at $\xi=1.0$ in the range of $N_{R}\left(0.0 \leq N_{R} \leq 2.0\right)$.

It is remarked here that the skin friction parameter $\left(\tau_{\mathrm{w}}\right)$ and velocity field $(\mathrm{F})$ is little affected by the thermal radiation parameter $\left(\mathrm{N}_{\mathrm{R}}\right)$ as it is present only in the energy equation.

\section{Conclusions}

The influence of thermal radiation on steady laminar incompressible MHD free convection boundary layer flow over a plate with viscosity variation parameter along with suction and injection have been obtained. It is found from the results that, the heat transfer decreases whereas the thickness of thermal boundary layer increases with the increase of thermal radiation parameter in case of both suction and injection.

\section{Acknowledgements}

The Authors expresses their gratitude to the Principal and Management of K.S. Institute of Technology for their continuous support towards their research work.

\section{References}

[1] E.M.Sparrow, R.D.Cess. FREE CONVECTION WITH BLOWING OR SUCTION. Journal of Heat Transfer. 83 (1961), pp.387-396. 
[2] J.H.Merkin. FREE CONVECTION WITH BLOWING AND SUCTION. Int. J. Heat Mass Transfer. 15 (1972), pp.989-999.

[3] J.F.Clarke. TRANSPIRATION AND NATURAL CONVECTION THE VERTICAL FLAT PLATE PROBLEM. Journal of Fluid Mechanics. 57 (1973), pp.45-61.

[4] K.R.Jayakumar, A.H.Srinivasa and A.T.Eswara. NATURAL CONVECTION MHD FLOW OVER A VERTICAL FLAT PLATE WITH SUCTION AND INJECTION. III National conference on emerging trends in Fluid Mechanics and Graph Theory, Christ University, Bangalore, Feb. 2012.

[5] A.T.Eswara, B.C.Bommaiah. THE EFFECT OF VARIABLE VISCOSITY ON LAMINAR FLOW DUE TO A POINT SINK. Ind. J. Pure Appl. Math. 35 (6); (2004), pp.811-815.

[6] K.R.Jayakumar, A.H.Srinivasa and A.T.Eswara, Nonsimilar MHD BOUNDARY LAYERS IN TWO-DIMENSIONAL FORCED FLOW WITH TEMPERATURE-DEPENDENT VISCOSITY, Journal of Current Sciences, 1 (2009), pp.407 - 417

[7] F.C.Lai, F.A.Kulacki, THE EFFECT OF VARIABLE VISCOSITY ON CONVECTIVE HEAT TRANSFER ALONG A VERTICAL SURFACE IN A SATURATED POROUS MEDIUM. Int. J. Heat Mass Transfer, 33 (1990), pp.1028-1031

[8] K.R. Jayakumar and A.T.Eswara VARIABLE VISCOSITY EFFECT ON MHD FREE CONVECTION FLOW OVER A POROUS PLATE WITH SUCTION AND INJECTION. Int. J of Mathematics and Computational Science. Vol.1. No.4. pp.153 - 159. 2015.

[9] J.R. Radbill, G.A.McCue. QUASILINEARIZATION AND NONLINEAR PROBLEMS IN FLUID AND ORBITAL MECHANICS. Elsevier, New York, (1970).

*Corresponding author.

E-mail address: krjkpjvrm@gmail.com 